\title{
Is there Any Reason of Irritating Vulvar Itching?
}

\author{
Magdalena Bizoń Szpernalowska* and Włodzimierz Sawicki \\ Chair and Department of Obstetrics, Medical University of Warsaw, Poland
}

*Corresponding author: Magdalena Bizoń Szpernalowska, Chair and Department of Obstetrics, Gynecology and Gynecological Oncology, ul. Kondratowicza 8, 03-242 Warsaw, Poland

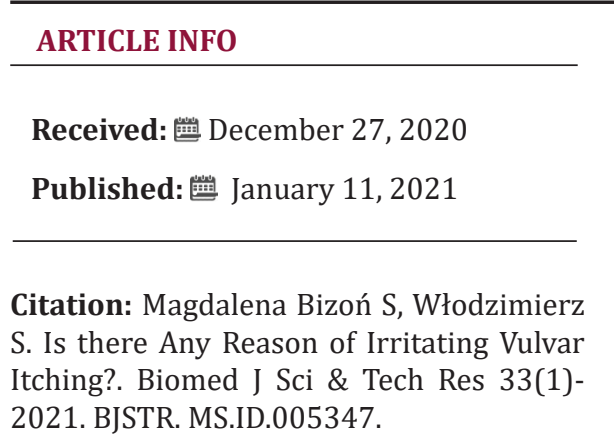

Abbreviations: LS: Lichen Sclerosus; PDT: Photodynamic Therapy; VIN: Vulvar Intraepithelial Neoplasia

\begin{abstract}
Vulvar complains like itching, burning and pain are reported mainly by women in peri- and postmenopuasal age. Severity of symptoms influence on well-being. The most frequent reason of vulvar symptoms is lichen sclerosus. Diagnose is given after vulvar biopsy, which is crucial in exact diagnosis. Sometimes histological result can also reveal hypertrophy of epithelium, acanthosis, lichen planus, vulvar intraepithalial neoplasia or even vulvar cancer. Lichen sclerosus cause leucoplacia, vulvar atrophy and narrowing of the vagina. Delay of diagnosis cause quicker progression of disease and intensification of vulvar symptoms. The first line of treatment is based on ointments according to glicocorticosteroids. If there is no response on this method, the alternative way is photodynamic therapy (PDT). The aim of the treatment is to protect against progression of lichen sclerosus and decrease vulvar symptoms.
\end{abstract}

Keywords: lichen sclerosus; itching; photodynamic therapy

\section{Mini Review}

Clinical vulvar symptoms like itching, burning and pain are irritable and annoying for women. Their severity and intensity induce scratching and in this way infection of the wound can appear. Epidemiological statistics show that every fifth woman complains of vulvar symptoms. It is estimated that $1,7 \%$ of all ambulatory visits in Outpatient Gynecologic Clinic concern on complains of vulvar syptoms [1]. The statistics show that women are more frequent diagnosed with lichen sclerosus than men in 6-10 times [2,3]. New changes of vulva sometimes causes patients problems and are a reason of visit to dermatologists, gynecologists, urologists, pediatrics, geriatricians and GPs. Methods of treatment are depended on specialists. Nevertheless, sometimes there is neccesity of co-operation between specialists [4]. The purpose of this mini review was to expose these problems of vaginal lichen sclerosus.

\section{Discussion}

\section{History of Lichen Sclerosus}

Lichen sclerosus was described for the first time by Hallopeau in 1887. Changes in anogenital area were called atrophic form of lichen planus [4]. In 1892 Darrier publicated features of histological view. Another names of lichen sclerosus were kraurosis vulvae, weissflechen dermatose and white spot disease [5]. Nomenclature include also term of lichen sclerosus and atrophicus [6]. In 1928 Stuhmer described similar disease in men wih occupied urethra and glans penis, which was called balanitis xerotica. Nowadays it is male equivalent of lichen sclerosus [7]. Finally name of lichen sclerosus was accepted in 1976 by ISSVD (International Society for the Study of Vulvovaginal Disease) [4]. Despite many modifications in nomenclature of vulvar disease, the name of LS does not changed.

\section{Epidemiology}

Epidemiological research show lichen sclerosus as a risk factor of neoplastic disease. In primary lichen sclerosus risk of vulvar and vaginal cancer increases. Lower morbidity in cervical cancer can be correlated with lower risk of infection of HPV. Patients with advanced stage of lichen sclerosus intercourse less often or even not because of atrophy and narrowing of the vagina. In that way they avoid HPV infection, which is transmitted in transvaginal way. Higher risk of endometrial cancer and ovarian cancer was not reported [8].The highest morbidity of neoplastic disease is breast cancer. Metastases of breast cancer in localization of vulva is rare and stands for $5-8 \%$ cases. Lobular cancer of the breast gives the most frequentmetastases for vulva in $10-15 \%$ cases [9]. 
On the other hand, only 2 cases of metastases of vulvar cancer to breast were described. Definitely more often metastates in breast come from ovarian cancer, endometrial cancer, cervical cancer and choriocarcinoma. Every change on the anogenital area in patient with cancer in the past should be checked histologically [10]. However, lichen sclerosus was noticed also in postradiated skin after radiotherapy because of breast cancer. It was discussed a case study of patient wih vaginal cancer with lichen sclerosus after brachytherapy [11]. Average time of ending of radiotherapy and first symptoms of lichen sclerosus was 2 to 12 years $[12,13]$. The main reccommendation of all vulvar diseases is everyday care of vulvar skin and avoid irritating factors like artificial underwear, using of detergens and dyes. Good results ae after emolients, soap substitute and soft, cotton underwear [14].

\section{Risk Factors}

One of the risk factors of lichen sclerosus is Human Papillomavirus Virus (HPV), like in cervical or vulvar cancer. There are registered more than 120 types of HPV virus [6]. Higher percentage of HPV infection in lichen sclerosus were recognized in male (29\%) than female (8\%) [15]. Human Papilloma Virus is a risk factor of cervical intraepithelial neoplasia and vulvar intraepithelial neoplasia. In metanalysis, correlation between infection of HPV and VIN was observed in $84 \%$ cases. Neoplastic transformation was claimed in $10 \%$ of patients [16]. What is a difference, higher expression of protein $\mathrm{p} 16$ was observed in vulvar HSIL and spinocellulare vulvar cancer dependend on HPV, which is the opposite to LS [17]. Undifferentiated VIN did not correlate with lichen sclerosus, but most frequent planoepitheliale vulvar cancer is observed [18]. In history, overexpression of p53 appears which can be a marker of vulvar cancer [19]. However, lichen sclerosus was recognized in area of differentiated VIN. Because of high risk of neoplastic transformation every new change should be biopted and histologically verify [20].

\section{Morphology}

The most often localization of lichen sclerosus, is anogenital area, which include labia majora, labia minora, area of clitoris and perianal area. Firstly, white plaques called leucoplacia appear, then they rupture. In that way cracks are presented, which cause scar and fibrosis till atrophy (Figure 1). Persistent symptoms induce reflexive scratching and can provide to subepithelial haemorrhages [21].After years vulva becomes like elephant skin with progressing atrophy. Labia get schrunk, in clitoris area burning is presented (Figure 2). Fibrosis and degeneration cause narrowing of urethra and generate dysuria problems. Similar pathomechanism is correlated with narrowing of vagina and sexual disorders appear. Sometimes leukoplakia located in perianal area looks like „eight” [22]. There were also described cases of lichen sclerosus in anogenital area in monozygotic twins [23].

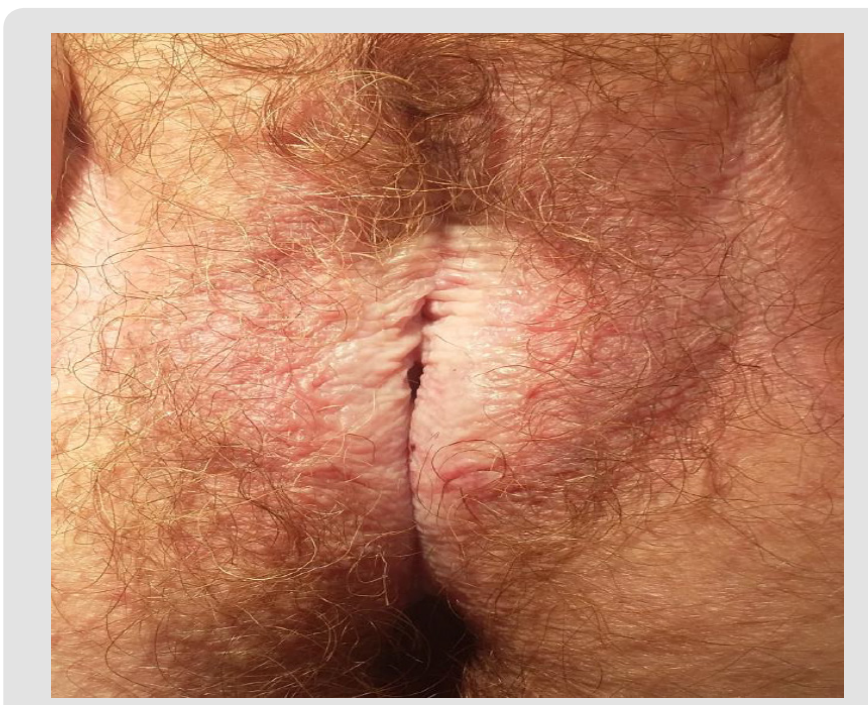

Figure 1: Lichen Sclerosus.

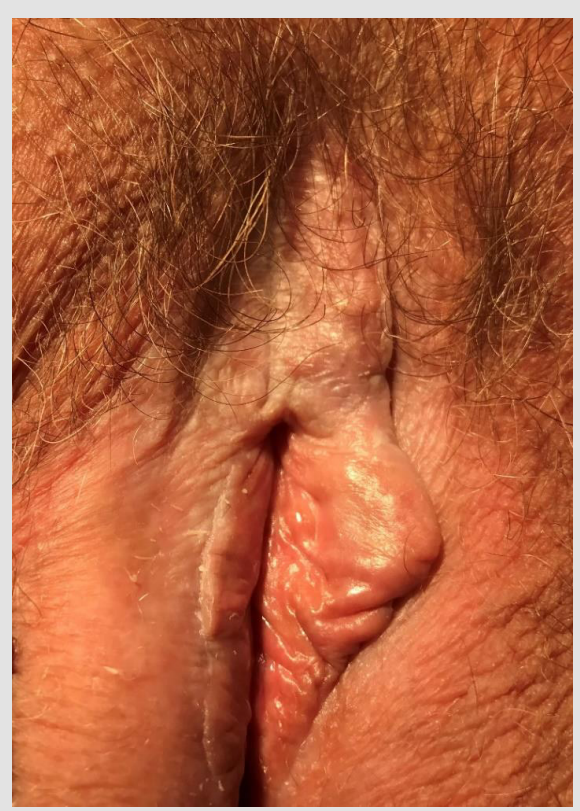

Figure 2: Lichen sclerosus.

It is also published co-existance of father and daughter [24]. On the other hand, family history of lichen sclerosus is a risk factor of vulvar cancer [25]. Children with lichen sclerosus had in $14 \%$ cases diagnose of autoimmunological diseases, on the other hand autoimmunological disorders were rejected in family history in $64 \%$ [26]. Higher correlation of autoimmune diseases and HLA antibodies were observed in women with LS than in men [27]. There are described many correlation with presence of LS. First of all, postmenopausal age with lower concentration of estrogens predispose for vaginal dryness and atrophy of vulva. Lichen sclerosus co-exists with autoimmunological diaseases. The most frequent are thyroid disease, malignant anemy, diabetes mellitus type 1 , albinism and alopecia areata [14]. 


\section{Treatment}

The first line of treatment of lichen sclerosus was glicocorticosteroidotherapy, which was firstly used in 1991 year [28]. Propioniate clobetasol has the most advantageous profits like reduction of symptoms and general improvement [14]. Unfortunately, this method should not be used permanently. After using specific algorithm remission of the disease should be seen. Index of reccurrence of lichen sclerosus after locally steroids was $82 \%$ [29]. Clobetasol was so effective like mometasone and shold be aplicated 8-12 weeks [30]. Totally remission of lichen sclerosus was after using propionian clobetasole [31]. There is a group of patietns which stands $4-10 \%$ cases with no responce on locally steroidotherapy in anogenital area. The second line of therapy stands for calcineurins inhibitors like tacrolimus and pimecrolimus [32]. But in comparison of clobetasol to pimecrolimus, the first one reduce inflammatory proccess and prevent neoplastic transformation of lichen sclerosus [33]. After therapy of pimecrolimus, higher concentration of antigen p53 in nucleus and keratinocytes is observed. Antigen p53 induces stress, anemy and inflammatory process. Spinocellulare vulvar cancer gives frequently neoplastic transformation than others [34].

\section{Photodynamic Therapy}

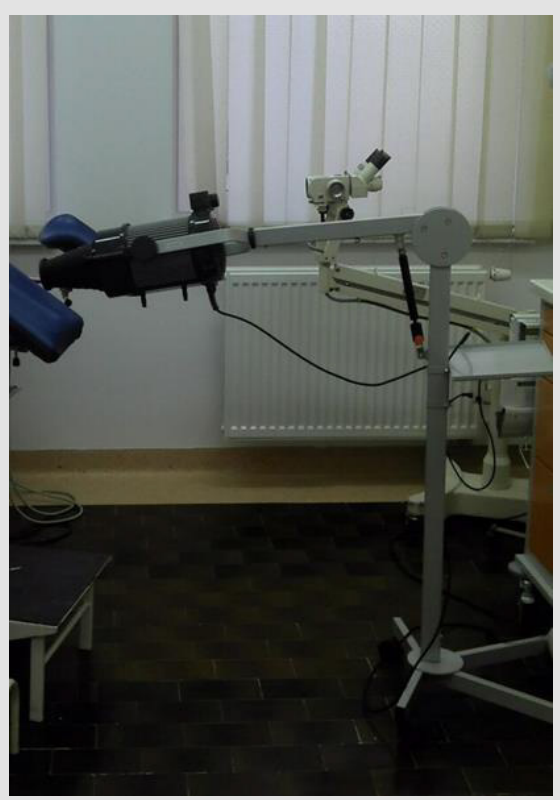

Figure 3: Lamp of photodynamic therapy.

The solar conception as a way of curing was known from ancient Egypt, India and Greece. In 1923 Alderson for the first time described phenomen of heliotherapy in treatment of psoriasis [35]. Therefore alternative method of treatment of lichen sclerosus seems to be photodynamic therapy (PDT) (Figure 3). The first photosensitizer was hematoporfirin. In 80s of XX century $\delta$-aminolevulinian acid was initiated as photosensitizer before PDT.
The first application in treatment of vulvar dermatose took place in 1993, when experimental research in vulvar intraepithelial neoplasia, cervical intraepithelial neoplasia and lichen sclerosus was conducted [36]. Positive effects of PDT was given also to extragenital localization [37].

Mechanism of PDT was based on oxidative proces after emition of light from photodynamic lamp towards vulvar skin with applicated prior 2 hours $\delta$-aminolevulinian acid. Methylated form of photosensitizer infiltrate in the vulvar skin and is cumulated there [38].

Photosensiziter has to sensitize tissue to get better accces of electromagnetic wave. Fibrosis of tissues, reduction of intensity of skin are caused by keratinocytes, which under control of light from PDT produce higher concentration of Il-1, TNF, metalloproteinase-1 and metalloproteinase-3 [39]. Photodynamic Therapy is also used in indications like condylomata accuminata, acnes, psoriasis, Darrier disease, sarcoidosis and penile lichen planus. Thanks to profits on skin and value on flexibility PDT has application in rejuvenation of the skin [38]. Surgical treatment is not dedicated in LS. Postoperative adhesions and wound cause dysfunction in anogenital area connected with urinary problems and dyscomfort in sexual life. On the other hand, surgery is the first line of therapy as local incision in VIN. In this cases also reconstructive surgery can be considered to avoid decreasing of self esteem [14].

\section{Conclusion}

Lichen sclerosus is the most frequent vulvar disease. The knowledge of symptoms and clinical features allows to recognize disease and begin treatment. The most important clue for patients is to carefully adjust to hygienic rules of vulvar area. Everyday using of oinments protect against reccurrence itching and burning. Earlier diagnosis and treatment, later atrophic complications appear. Neglected visit in gynecological outpatient clinic reduce quality of life. On the other hand, in some cases lichen sclerosus can transformed into VIN or vulvar cancer, where different methods of treatment are used.

\section{Conflict of Interest}

The authors have no conflicts of interest to declare.

\section{References}

1. Brodrick B, Belkin ZR, Goldstein AT (2013) Influence of treatments on prognosis for vulvar lichen sclerosus: facts and controversies. Clinics in Dermatology 31: 780-786.

2. Boero V, Brambilla M, Sipio E, Liverani CA, Di Martino M, et al. (2015) Vulvar lichen sclerosus: a new regenerative approach through fat grafting. Gynecologic Oncology 139: 471-475.

3. Lima RSA, Schettini APM, Maquine GA, Santos M (2015) Bullous and hemorrhagic lichen sclerosus - case report. An Bras Dermatol 90 (3Suppl 1) : 118-120.

4. Powell JJ, Wojnarowska F (1999) Lichen sclerosus. Seminar. The Lancet 353: 353(9166):1777-1783. 
5. Wakelin SH, Marren P (1997) Lichen sclerosus in women. Clinics in Dermatology 15: 155-169.

6. Fistarol S, Itin P (2013) Diagnosis and treatment of lichen sclerosus. Am J Clin Dermatol 14: 27-47.

7. Michajłowski I, Matuszewski M, Michajłowski J, Sobjanek M, Wlodarkiewicz A, et al. (2008) Liszaj twardzinowy i zanikowy męskich narządów płciowych. Polish Journal of Urology 61/1.

8. Halonen P, Jakobsson M, Heikinheimo O, Riska A, Gissler M. et al. (2017) Lichen sclerosus and risk of cancer. Int J Cancer 140: 1998-2002.

9. Alligood-Percoco N, Kessler M, Willis G (2015) Breast cancer metastasis to the vulva 20 years remote from initial diagnosis: a case report and literature review. Gynecologic Oncology Reports 13: 33-35.

10. Papatheodorou DC, Liakou CG, Kalogerakos K, Dimopoulos JCA, Kalinoglou (2017) Bilateral breast metastases from vulvar carcinoma: a case report and literature review. Case reports in Obstetrics and Gynecology, article ID 1357203.

11. Edwards LR, Privette ED, Patterson JW, Tchernev G, Chokoeva A, et al. (2017) Radiation-induced lichen sclerosus of the vulva. Wien Med Wochenschr 167: 74-77.

12. Yates V (1985) Lichen sclerosus et atrophicus following radiation therapy. Arch Dermatol 121 (8): 1044-1047.

13. Vujovic O (2010) Lichen sclerosus in a radiated breast. CMAJ 182 (18).

14. (2011) The management of vulval skin disorders. Royal College of Obstetricians and Gyneacologist Green-top Guideline 58.

15. Hald A, Blaakaer J (2018) The possible role of human papillomavirus infection in the development of lichen sclerosus. Int J Dermatol 57: 139146.

16. Wakeham K, Kavanagh K, Cuschieri K, Millan D, Pollock KG (2017) HPV status and favourable outcome in vulvar squamous cancer. Int J Cancer 140: $1134-1146$.

17. Neffen F, Loning T, Crum C, Riethdorf L (2004) p16INK4A expression as biomarker for HPV 16-related vulvar neoplasias. Human Pathology 35(12): 1477-1483.

18. Vilmer C, Cavelier-Balloy B, Nogues C, Trassard M, Le Doussal V (1998) Analysis of laterations adjacent to invasive vulvar carcinoma and their relationship with the associated carcinoma: a study of 67 cases. Eur J Gynaecol Oncol 19 (1): 25-31.

19. Hantschmann P, Sterzer S, Jeschke U, Friese K (2005) p53 expression in vulvar carcinoma, vulvar intraepithelial neoplasia, squamous cel hyperplasia and lichen sclerosus. Anticancer Research 25: 1739-1746.

20. Hoang LH, Park KJ, Soslow RA, Murali R (2016) Squamous precursor lesions of the vulva: current classification and diagnostic challenges. Pathology 48(4): 291-302.

21. Sadowska-Przytocka A, Dańczak-Pazdrowska A, Szewczyk A, CzarneckaOperacz M, Jenerowicz D, et al. (2012) Treatment of genital lichen sclerosus in women-review. Ginekol Pol 83: 458-461.

22. Perez-Lopez FR, Ceausu I, Depypere H, Tamer Erel C (2013) EMAS clinical guide: vulvar lichen sclerosus in peri and postmenopausal women. Maturitas 74: 279-282.

23. Doulaveri G, Armira K, Kouris A, Karypidis D, Potouridou I (2013) Genital vulvar lichen sclerosus in monozygotic twin women: a case report and review of the literaturę. Case Rep Dermatol 5: 321-325.
24. Meyrick T, Ridley CM, McGibbon DH, Black MM (1996) Anogenital lichen sclerosus in women J R Soc Med 89: 694-698.

25. Sherman V, McPherson T, Baldo M, Salim A, Gao XH (2010) The high rate of familial lichen sclerosus suggests a genetic contribution: an obserwational cohort study. J Eur Acad Dermatol Venereol 24(9): 10311034.

26. Senturk N, Aydin F, Birinci A, Yildiz L (2004) Coexistence of HLA-B*08 and HLA-B*18 in Four Siblings with Lichen slcerosus. Dermatology 208: 64-66.

27. Azurdia RM, Luzzi GA, Byren I. Welsh K (1999) Lichen sclerosus in adult men: a study of HLA associations and susceptibility to autoimmune disease. British Journal of Dermatology 140: 79-83.

28. Ellis E, Fischer G (2015) Prepubertal-onset vulvar lichen sclerosus: the importance of maintenance therapy in long-term outcomes. Pediatric Dermatology 32: 461-467.

29. Baskan EB, Turan H, Tunali S, Toker SC, Saricaoglu H (2007) Open-label trial of cyclosporine for vulvar lichen sclerosus. J Am Acad Dermatol 57: 276-278.

30. Virgili A, Minghetti S, Borghi A, Corazza M (2013) Proactive maintenance therapy with a topical corticosteroid for vulvar lichen sclerosus: preliminary results of a randomized study. British Journal of Dermatology 168: 1316-1324.

31. Funaro D, Lovett A, Leroux N, Powell J (2014) A double-blind, randomized prospective study evaluating topical clobetasol propionate $0.05 \%$ versus topical tacrolismus $0.1 \%$ in patients with vulvar lichen sclerosus. J Am Acad Dermatol 71: 84-91.

32. Goldstein A.T, Thaci D, Luger T (2009) Topical calcineurin inhibitors for the treatment of vulvar dermatoses. European Journal of Obstetris\&Gynecology and Reproductive Biology 146: 22-29.

33. Brodrick B, Belkin ZR, Goldstein AT (2013) Influence of treatments on prognosis for vulvar lichen sclerosus: facts and controversies. Clinics in Dermatology 31: 780-786.

34. Nissi R, Kotila V, Knuuti E, Vaare PO, Kaupilla S, et al. (2009) p53 and $\mathrm{Bcl}-2$ expression in keratinocytes of vulvar lichen sclerosus during pimecrolimus treatment. British Journal of Dermatology 161: 948-970.

35. Schneider LA, Hinrichs R, Scharffetter-Kochanek K (2008) Phototherapy and photochemotherapy. Clinics in Dermatology 26: 464-476.

36. Ascencio M, Collinet P, Cosson M, Vinatier D, Mordon S (2007) Interet et place de la therapie photodynamique en gynecologie. Gynecologie Obstetrique \& Fertilite 35: 1155-1165.

37. Kroft EBM, Berkhof NJG, Van de Kerkhof PCM, Gerritsen RMJP, De Jong EMGJ (2008) Ultraviolet A phototherapy for sclerotic skin diseases: a systematic review. J Am Acad Dermatol 59: 1017-1030

38. Mitra A, Stables GI (2006) Topical photodynamic therapy for noncancerous ski conditions. Review. Photodiagnosis and Photodynamic Therapy 3: 116-127.

39. Buggiani G, Troiano M, Rossi R, Lotti T (2008) Photodynamic therapy: Off-label and alternative use in dermatological practice. Photodiagnosis and Photodynamic Therapy 5: 134-138. 
ISSN: 2574-1241

DOI: 10.26717/BJSTR.2021.33.005347

Magdalena Bizoń Szpernalowska. Biomed J Sci \& Tech Res

(C) 9 This work is licensed under Creative

Submission Link: https://biomedres.us/submit-manuscript.php

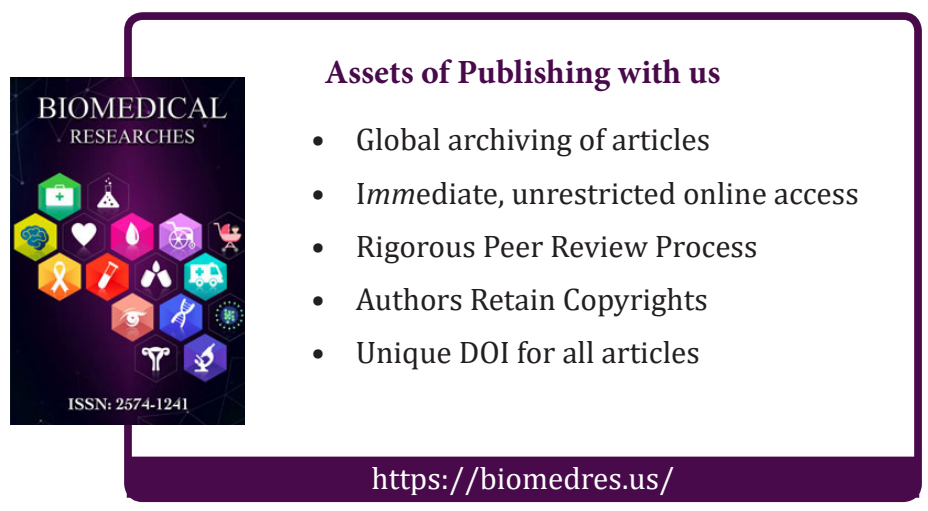

